\title{
UNA PEQUEÑA LÁMINA DE PLOMO CON INSCRIPCIÓN IBÉRICA DE PALEOGRAFÍA ARCAICA DEL PICO DE LOS AJOS (YÁTOVA, VALÈNCIA)
}

\section{A SMALL SHEET OF LEAD WITH IBERIAN INSCRIPTION OF ARCHAIC PALAEOGRAPHY FROM PICO DE LOS AJOS (YÁTOVA, VALĖNCIA)}

\author{
Joan Ferrer i Jané*, Javier Velaza Frías \\ Universitat de Barcelona. Littera
}

\author{
David Quixal Santos, Ana Serrano Castellano, Consuelo Mata Parreño \\ Departament de Prehistòria, Arqueologia i Història Antiga. GRAM \\ Trinidad Pasíes Oviedo \\ Museu de Prehistòria de València \\ Gianni Gallello \\ Departament de Prehistòria, Arqueologia i Història Antiga. PREMEDOC
}

\begin{abstract}
RESUMEN. En este trabajo editamos una pequeña lámina de plomo hallada en el Pico de los Ajos (Yátova) en la campańa de 2018. La lámina apareció plegada y contiene una inscripción ibérica de una sola línea en cada cara que muy probablemente configure un solo texto completo. Sus características formales son poco comunes, siendo el paralelo más cercano el de las láminas votivas de El Amarejo. La presencia del elemento kutuŕ, frecuente en las inscripciones votivas rupestres, también apuntaría a una interpretación religiosa. Desde el punto de vista paleográfico, cabe señalar que se trata de un texto explícitamente dual, ya que conviven en él las dos variantes de te y ŕ. A pesar de que el contexto arqueológico de su amortización tiene una cronología de finales del s. II a.C. o principios del s. I a.C., este nuevo plomo presenta una paleografía arcaica, quizás incluso del s. Iv a.C. Esto se explicaría bien por el hecho de aparecer en un edificio dedicado al reciclaje de objetos metálicos, siendo en ese momento la lámina solo un objeto metálico más, fuera de su contexto original.
\end{abstract}

PALABRAS CLAVE: plomo escrito, oppidum, Edad del Hierro, cultura ibérica, pXRF, restauración.

ABSTRACT: In this paper we edit a small sheet of lead found in the Iberian site of Pico de los Ajos (Yátova) in the 2018 campaign. The sheet appeared folded and it contains an Iberian inscription of one line on each side that most likely forms a single full text. Its formal characteristics are uncommon, the closest parallel being the votive lead sheets of the site of El Amarejo. The presence of the kutur element, frequent in rock votive inscriptions, would also invite to a religious interpretation. From the palaeographic point of view, it should be noted that this is an explicitly dual text, due to the convivence of the two variants of the signs te and $\mathbf{r}$. Although the archaeological context of its amortization has a chronology of the end of the $2^{\text {nd }}$ century BC or early $1^{\text {st }}$ century BC, this new lead sheet presents an archaic palaeography, perhaps even from the $4^{\text {th }}$ century BC. This would be well explained because the lead sheet has appeared in a building dedicated to the recycling of metal objects, being at that time only one more metal object, out from its original context.

KEYWORDS. lead written sheet, oppidum, Iron Age, Iberian culture, pXRF, restoration.

* Correspondencia a / Correspondence to: Joan Ferrer i Jané, Grup Littera (Universitat de Barcelona). C/ Tallers, 22bis-4t 7. (08001 Barcelona) joan.ferrer.i.jane@gmail.com - https://orcid.org/0000-0002-6596-7437.

Cómo citar / How to cite: Ferrer i Jané, Joan; Quixal Santos, David; Velaza Frías, Javier; Serrano Castellano, Ana; Mata Parreño, Consuelo; Pasíes Oviedo, Trinidad; Gallello, Gianni (2021), "Una pequeña lámina de plomo con inscripción ibérica de paleografía arcaica del Pico de los Ajos (Yátova, València)", Veleia, 38, 91-109. (https://doi.org/10.1387/veleia.22508).

Recibido: 29 enero 2021; aceptado: 25 febrero 2021.

ISSN 0213-2095 - eISSN 2444-3565 / (C) 2021 UPV/EHU 


\section{Presentación y Contexto del hallazgo}

La pieza que presentamos fue hallada en 2018 en el Pico de los Ajos (Yátova, València), un poblado ibérico fortificado que estuvo habitado al menos desde el siglo viI a.C. hasta época romana imperial (Quixal 2010; Quixal et al. 2018). Está ubicado en una cima secundaria de Sierra Martés, a más de $1.000 \mathrm{~m}$ de altitud, y tiene una extensión aproximada de unas 3 ha (fig. 1). Su altitud le permite una amplia visibilidad del curso del río Magro, una importante vía de comunicación en época ibérica que conectaba las planicies litorales con el interior meseteño (Quixal 2012). Este oppidum, por su ubicación, tendría un destacado papel en la articulación y delimitación de los territorios de las ciudades ibéricas de La Carència (Torís, València) y Kelin (Caudete de las Fuentes, València). Conserva en su extremo sureste, el lado más accesible, las principales estructuras defensivas: un foso excavado en la roca, una torre adosada a él y un tramo de muralla (Díes \& Gimeno 1995).

Una de las razones que impulsó la popularidad de este yacimiento y, desafortunadamente, también la continua acción expoliadora que ha sufrido, fue el descubrimiento en 1979 de unos plomos escritos en ibérico, publicados por Domingo Fletcher justo un año después (Fletcher 1980), a los que rápidamente se sumaron otros textos, también sobre plomo, actualmente depositados en el Museu de Prehistòria de València (Fletcher 1982 y 1985; Tomás 1989). La importancia de este nuevo hallazgo, denominado PA-VII ${ }^{1}$, radica en que es el primer plomo escrito procedente de una excavación arqueológica reglada y, por lo tanto, contextualizado.
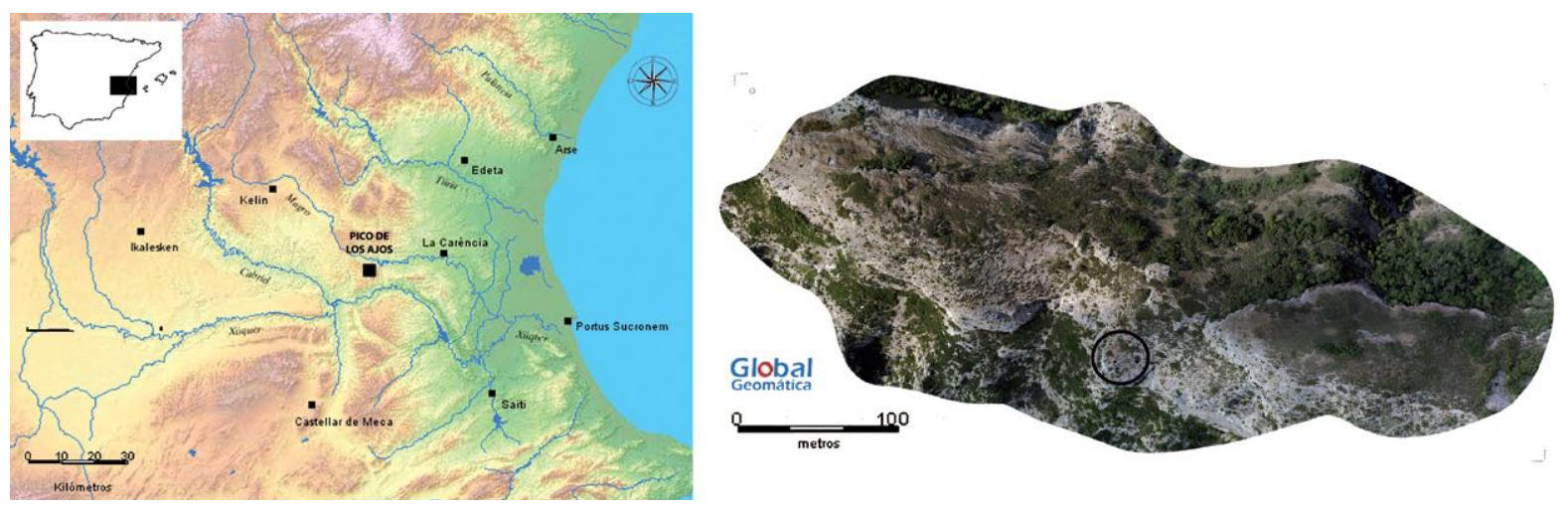

Figura 1. Mapa de ubicación del yacimiento y ortofoto donde se indica el lugar del hallazgo.

El yacimiento ha sido, hasta la fecha, objeto de cuatro campañas (2017-2020)2. El plomo PA-VII procede del denominado sector 4, un espectacular espolón natural algo apartado del grueso del asentamiento, orientado hacia el sur, dominando el llano de Venta Gaeta (Cortés de Pallás, València) que fue excavado prácticamente en su totalidad entre 2017 y 2018 . En él se do-

1 Depositado en el Museu de Prehistòria de València, inv. N.o 45899.

2 Los trabajos se iniciaron fruto de un convenio de colaboración entre el Ayuntamiento de Yátova y la Universitat de València, y desde 2019 han pasado a integrarse dentro el programa anual de excavaciones arqueológicas del Museu de Prehistòria de València. 
cumentó un edificio articulado en cuatro espacios, de los que uno claramente era un departamento techado (E2), completado con otras estancias abiertas o semicubiertas de carácter auxiliar (Quixal et al. 2019) (fig. 2).

En estos cuatro espacios se recuperaron, además de materiales cerámicos, una moneda ibérica y un interesante conjunto de piezas metálicas de bronce, hierro y plomo. Las cerámicas ibéricas son mayoritarias y se trata, principalmente, de recipientes de almacenaje y transporte. Las escasas importaciones proceden del ámbito itálico (ánforas campanas, barniz negro y microvasos de paredes finas). Estas, junto a un semis de Kese, permiten fechar el abandono del lugar entre finales del s. II e inicios del i a C. El grupo de más de 20 piezas y fragmentos metálicos se localizó, en su mayoría, en el Espacio 2 (fig. 2). Está compuesto, entre otros fragmentos indeterminables, por dos preformas, un clavo y la hoja de unas tijeras de hierro; tres ponderales, tres espátulas lanceoladas, fíbulas y fragmentos de fíbulas, en bronce; y el plomo, objeto principal de este estudio, en el que se apreciaban varios signos escritos (fig. 3, 1). Se trata de un conjunto heterogéneo de piezas incompletas, rotas o inutilizadas intencionadamente. Por ejemplo, ninguna de las fíbulas está completa; los tres ponderales no forman parte de la misma serie y las tres espátulas aparecen dobladas por el mango de manera similar. Todo ello nos lleva a pensar que se trata de una acumulación de material obsoleto con la finalidad de reciclarlo (Quixal et al. 2019; Serrano 2020).

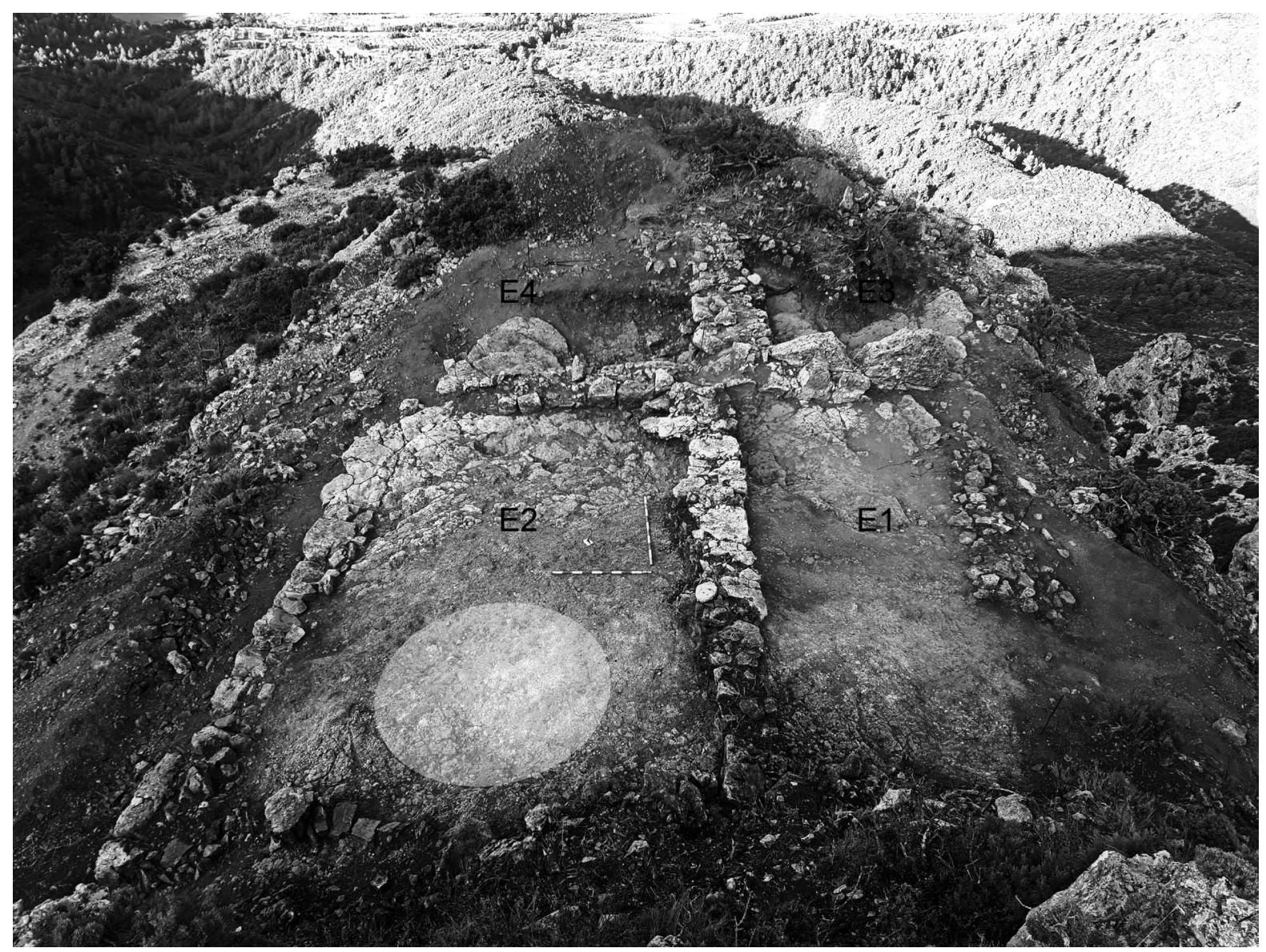

Figura 2. Vista del edificio del sector 4. El círculo indica la zona de concentración de metales. 


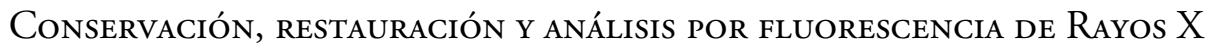

\section{Intervención de conservación y restauración}

Para preservar la lámina de plomo epigráfico había que protegerla contra su proceso natural de deterioro. De hecho, este tipo de materiales son muy vulnerables a la degradación desde el mismo momento del enterramiento, donde la presión del terreno los deforma y el proceso de carbonatación los vuelve quebradizos (Degrigny \& Le Gall 1999; Forrières 2001).

Además, la problemática especial de esta pieza, que se encontró doblada sobre sí misma hasta tomar una forma cuadrangular, hacía necesaria la realización no solo de un tratamiento de limpieza, sino de un proceso de desdoblado que permitiese la lectura del epígrafe sin dañar la blanda superficie del plomo. Su estado de conservación era extremadamente frágil, estaba aplastada, presentaba algunas microfisuras y pequeñas pérdidas de material, y tenía algún pequeño fragmento a punto de desprenderse de la plancha. A pesar de estar cubierta por capas de carbonatos, eran reconocibles a simple vista algunas letras incisas sobre la superficie, por lo que el objetivo principal de la intervención era el desdoblado del plomo para proceder a su posterior estudio (fig. 3). De hecho, a pesar de las dificultades que entrañaba esta delicada operación, ya que se trata de una lámina muy fina $(<1 \mathrm{~mm})$, la legibilidad documental debía garantizarse, porque en casos como este no solo hay que asegurar la estabilidad del material con el que está fabricado el objeto, sino dar especial relevancia a su consideración como documento histórico (Barrio et al. 2005).
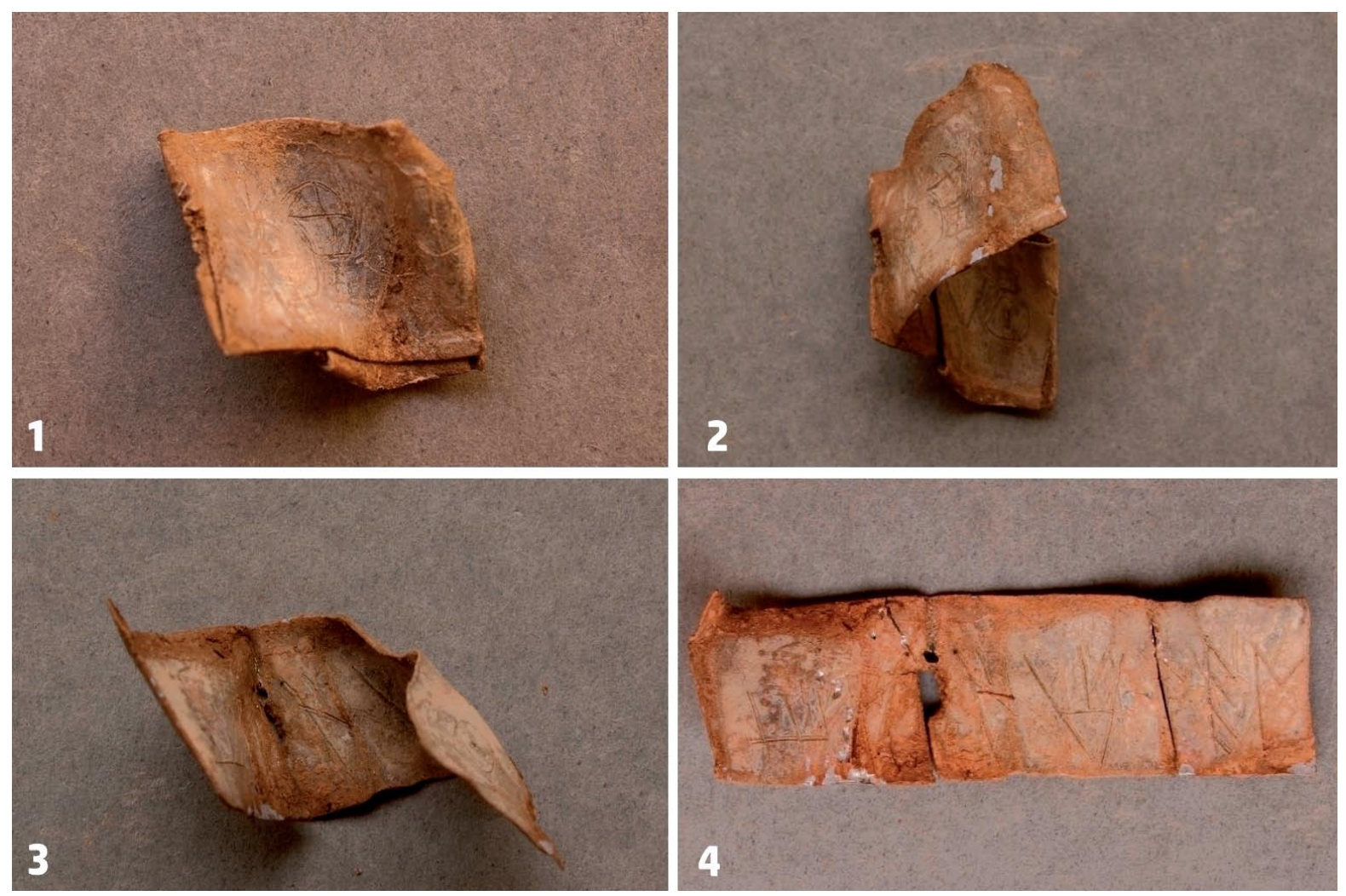

Figura 3. Proceso de desdoblado de la lámina de plomo. Imágenes correspondientes a cuatro de las fases. Archivo SIP del Museu de Prehistòria de València. 
Descartamos cualquier intento de limpieza con instrumental mecánico que pudiera rayar el plomo, como sabemos un material con bajo índice de dureza, donde se corría el riesgo de interferir en la correcta lectura de los caracteres escritos. El primer paso, por tanto, fue un sencillo tratamiento de limpieza suave con finas brochas bajo lupa binocular, para eliminar los restos de tierra superficial. A continuación, se procedió a su desdoblado con la ayuda de un soplador de aire caliente (Leister()), con el que se puede aplicar la temperatura de forma regulada y controlada (Burriel et al. 2011, 201). Para la apertura de los distintos pliegues se empleó instrumental de madera y, con extremo cuidado, se fue logrando abrir el plomo e ir descubriendo los distintos signos epigráficos por ambas caras. Se documentó todo el proceso perfectamente y, a continuación, se procedió a ultimar el proceso de limpieza (fig. 4).

Para eliminar la capa de incrustación calcárea que cubría la lámina se recurrió a un tratamiento de impregnación por inmersión en una disolución al 5\% de EDTA tetrasódico, y con la ayuda de pequeñas brochas se pudo ir limpiando la superficie hasta que los caracteres se leyeron perfectamente. Para adherir algunas uniones por donde el plomo estaba separado se empleó resina epoxídica y alguna pequeńa pérdida de material fue reintegrada con resina acrílica y pigmentos, por tal de darle un mayor refuerzo a la zona. Al finalizar colocamos por impregnación una doble capa de protección: la primera de resina acrílica Paraloid B72 al 5\%, y la segunda de cera microcristalina Cosmoloid al 5\% (fig. 4). Terminada la intervención se diseñó un tipo de contenedor totalmente hermético, a modo de caja nido, con control de humedad para garantizar la conservación preventiva de la pieza (Díaz \& García 2015, 43-45).
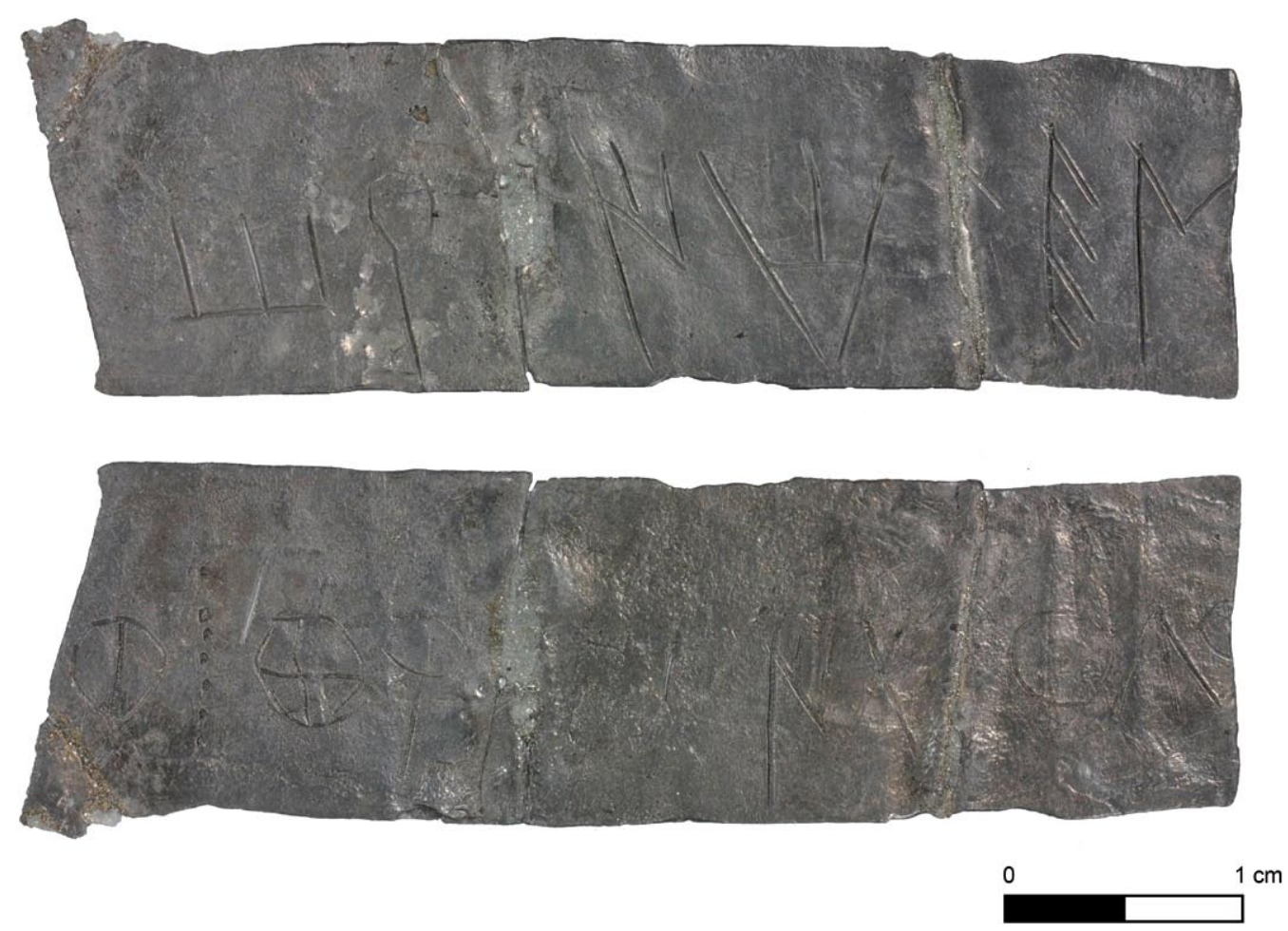

Figura 4. Plomo limpio y restaurado (inv. 45899). Archivo SIP del Museu de Prehistòria de València. 
Análisis por fluorescencia de Rayos $X$

La lámina de plomo se ha analizado con un equipo portátil de fluorescencia de rayos X (pXRF) para identificar su perfil elemental y caracterizar su composición. Se han medido 12 puntos por triplicado (figs. 5 y 6), seis puntos en la cara B (M1-M6) y otros seis puntos en la cara A (M7-M12).
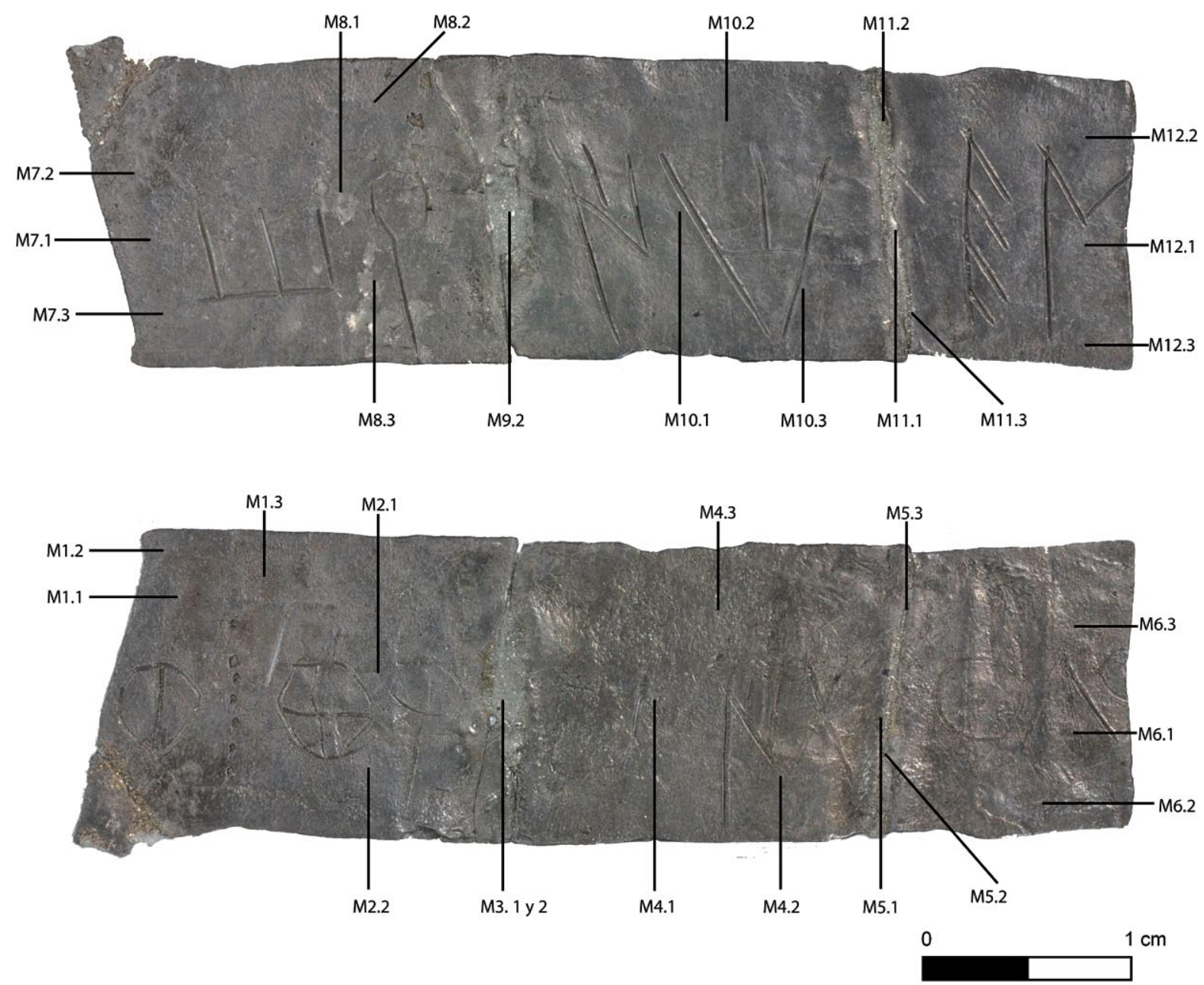

Figura 5. Puntos de medidas por $p X R F$.

Los puntos se han analizado directamente sin tratamiento previo utilizando un espectrómetro portátil S1 Titan de Bruker (Kennewick, Washington, USA) equipado con un tubo de Rodio y un detector and X-Flash ${ }^{\oplus}$ SDD. Se han empleado los softwares S1RemoteCtrl y S1Sync para el control del instrumento. El método Alloy se ha empleado para llevar a cabo el análisis de metales $(\mathrm{Ru}-$ bio-Barberá et al. 2019; Mata et al. 2020).

Como se muestra en la tabla 1 la lámina presenta niveles elementales muy similares en todos los puntos medidos, siendo el elemento mayoritario el plomo (alrededor de 95\%). Otros elementos minoritarios, que suman alrededor del 5\%, incluyen el cobre (alrededor del 3\%), el estańo $(0.2 \%)$ 
y la plata $(0.03 \%)$. Aunque debido a las características analíticas de los equipos empleados los resultados pueden variar, el perfil elemental identificado en la lámina del Pico de los Ajos es similar al plomo escrito del Tos Pelat (Moncada, València) donde el elemento mayoritario es el plomo y el cobre está presente en un porcentaje elevado en comparación con otros elementos minoritarios (Burriel et al. 2011). Otros elementos como la plata y el estaño, presentes como impurezas en la lámina estudiada podrían estar relacionados con el proceso de manufacturación del artefacto, pero no podemos compararlo con la pieza de Tos Pelat debido a las limitaciones relacionadas con la sensibilidad de los equipos empleados. En cambio, el análisis de un caracol de plomo (datos no publicados), encontrado en Puntal dels Llops (Olocau, València) (Bonet \& Mata 2002, 160), las proporciones de elementos identificados son estadísticamente las mismas que en PA-VII.

\begin{tabular}{cccc} 
LAB N. & Nombre & ID & Pb \% \\
\hline 213 & LAMINA Pb A & M7.1 & 95.0 \\
214 & LAMINA Pb A & M7.2 & 94.9 \\
215 & LAMINA Pb A & M7.3 & 94.8 \\
216 & LAMINA Pb A & M8.1 & 94.8 \\
217 & LAMINA Pb A & M8.2 & 95.1 \\
218 & LAMINA Pb A & M8.3 & 94.8 \\
220 & LAMINA Pb A & M9.2 & 95.0 \\
221 & LAMINA Pb A & M9.2 & 95.0 \\
222 & LAMINA Pb A & M10.1 & 94.9 \\
223 & LAMINA Pb A & M10.2 & 94.9 \\
224 & LAMINA Pb A & M10.3 & 94.9 \\
225 & LAMINA Pb A & M11.1 & 94.9 \\
226 & LAMINA Pb A & M11.2 & 95.0 \\
227 & LAMINA Pb A & M11.3 & 95.2 \\
228 & LAMINA Pb A & M12.1 & 94.7 \\
229 & LAMINA Pb A & M12.2 & 95.0 \\
230 & LAMINA Pb A & M12.3 & 94.9 \\
& & MEAN & $\mathbf{9 4 . 9}$ \\
& & SD & $\mathbf{0 . 1 2}$
\end{tabular}

\begin{tabular}{cccc} 
LAB N. & Nombre & ID & Pb \% \\
\hline 196 & LAMINA Pb B & M1 & 94.9 \\
197 & LAMINA Pb B & M1.2 & 94.6 \\
198 & LAMINA Pb B & M1.3 & 94.9 \\
199 & LAMINA Pb B & M2.1 & 94.9 \\
200 & LAMINA Pb B & M2.2 & 94.8 \\
201 & LAMINA Pb B & M2.3 & 94.9 \\
202 & LAMINA Pb B & M3.1 & 95.0 \\
203 & LAMINA Pb B & M3.2 & 95.0 \\
204 & LAMINA Pb B & M4.1 & 94.9 \\
205 & LAMINA Pb B & M4.2 & 94.9 \\
206 & LAMINA Pb B & M4.3 & 94.8 \\
207 & LAMINA Pb B & M5.1 & 94.9 \\
208 & LAMINA Pb B & M5.2 & 94.9 \\
209 & LAMINA Pb B & M5.3 & 94.9 \\
210 & LAMINA Pb B & M6.1 & 94.9 \\
211 & LAMINA Pb B & M6.2 & 94.9 \\
212 & LAMINA Pb B & M6.3 & 95.0 \\
& & MEAN & $\mathbf{9 4 . 9}$ \\
& & SD & $\mathbf{0 . 0 9}$
\end{tabular}

Figura 6. Análisis por pXRF. Resultados en porcentaje (\%). Mean: Media; SD: Desviación estándar.

Estos resultados pueden ayudar a reconstruir problemáticas relacionadas con el aprovisionamiento de materias primas, su proceso de manufacturación y contextualizar la lámina estudiada espacial y cronológicamente. No obstante, hay que llevar a cabo más analíticas en distintas piezas para la obtención de datos más robustos que puedan avalar las hipótesis relacionadas con materias primas, manufacturación, territorio y cronología.

\section{DESCRIPCIÓN Y COMENTARIO EPIGRÁFICO 3}

Se trata de una lámina de plomo con texto en ambas caras que tiene una forma ligeramente trapezoidal, de unos $5 \mathrm{~cm}$ de largo en el lado más largo y unos 4,7 en el más corto, mientras que su

${ }^{3}$ Este trabajo ha sido realizado en el marco del proyecto de investigación PID2019-105650GB-I00 y del GRC LITTERA (2017SGR241). 
altura oscila entre 1,3 y $1,5 \mathrm{~cm}$ y su grosor es inferior a $1 \mathrm{~mm}$. La extrema delgadez de la lámina ha causado que algunos de los trazos la atraviesen, como es claramente el caso del trazo central del signo to $\mathrm{y}$, parcialmente, de los dos trazos laterales. Además, probablemente esta sea la causa del orificio semicircular que presenta en su parte central, puesto que coincide con la presencia en ambas caras de las formas semicirculares de la cabeza de los signos a. La lámina está indudablemente completa tanto por la parte superior como por la inferior, mientras que la distancia del primer signo de la cara A respecto del lateral izquierdo sugiere que también está completa por este lado. En cambio, los signos fragmentados del lateral derecho, sin duda en la cara B y probablemente también en la cara A, indican que está incompleto por este lado. No obstante, el fragmento perdido debería ser pequeño, justo lo suficiente para trazar completos los signos fragmentados y una pequeña porción exenta hasta el lateral original. Esto puede deducirse a partir de la longitud de las secciones de los pliegues del plomo, ya que normalmente esta suele ir de menor a mayor, puesto que, a medida que aumenta el grosor de la lámina plegada, aumenta la longitud de la siguiente sección. Así pues, dado que la última sección es de unos $20 \mathrm{~mm}$ y la intermedia de unos $17 \mathrm{~mm}$, el fragmento perdido corresponde a la primera sección, que debería estar sobre los $15 \mathrm{~mm}$, pero solo mide $10 \mathrm{~mm}$, por lo que podemos estimar una pérdida máxima de unos $5 \mathrm{~mm}$.

Esta hipótesis se ve confirmada por la sombra de la corrosión de la segunda sección, que marca la longitud que tenía la primera, y confirma que la longitud actual es la del plomo plegado en su última configuración, por lo que queda una distancia de unos $5 \mathrm{~mm}$ hasta el límite del pliegue, que sería el máximo espacio perdido (fig. 7). En todo caso, no se puede garantizar que el plegado se ajustara perfectamente a la longitud de cada sección, por lo que, sin la identificación de signos fragmentados, no se podría confirmar la pérdida de ningún fragmento.

Sea como fuese, la pérdida del fragmento se produjo en algún momento de la vida del plomo anterior a su amortización final, puesto que en este último momento estaba protegida, al ser el extremo de la sección interior. Además, no se aprecia rotura discontinua ni erosión, sino más bien corte limpio. La única duda es si tendría sentido un recorte voluntario de tan escasas dimensiones.

Alternativamente, aunque parece poco probable, se podría especular con una lámina más larga que justificara un recorte voluntario de una porción significativa. Esta circunstancia sería posible en el supuesto de que hubiera existido otra sección de pliegue. En todo caso, la nueva primera sección debería ser de longitud menor a la estimada para la actual, por lo que no podría ser mayor de entre 10 y $12 \mathrm{~mm}$, espacio que permitiría representar un par de signos o tres. Y, de existir una ulterior sección, su tamaño solo permitiría añadir un signo más. Aún menos probable sería que originalmente la lámina escrita fuera más larga y no estuviera plegada, de forma que el plegado fuera solo un producto de su amortización final.

En cualquier caso, todo apunta a que la lámina apareció en un contexto secundario, probablemente muy distinto y cronológicamente lejano del que la alojó inicialmente, siendo en este último momento solo un objeto metálico más, como confirma el contexto de hallazgo y su cronología. Esta circunstancia se repite en los tres plomos mayores del yacimiento (BDH ${ }^{4}$ V.13.01-03), que también aparecen recortados por un mismo corte cuando los tres formaban un solo bloque metálico (Ferrer i Jané 2021).

La altura de los signos de la cara A oscila entre los $4 \mathrm{~mm}$ del signo to y los $10 \mathrm{~mm}$ del signo i, mientras que el resto mantiene una altura homogénea entre los 8 o $9 \mathrm{~mm}$. En la cara B los signos

\footnotetext{
4 Base de Datos Hesperia: http://hesperia.ucm.es/ hesperia/Generalidades.php
} 
son claramente de menor módulo, de forma que los de mayor altura son ŕ, a e i de $7 \mathrm{~mm}$, ta de 6, mientras que el resto oscila entre 4 y $5 \mathrm{~mm}$.

Respecto al orden de lectura, el signo aislado delante del separador en la cara B indica que la inscripción empieza por el texto de la cara A, circunstancia apoyada también por el mayor módulo de los signos de la cara A, que indica que se trazó con mayor libertad. Una vez escrito el texto en la cara A, se volteó la lámina por la base y se procedió a escribir el texto de la cara B.

Las fotografías del plomo aún doblado y el tamaño creciente de las secciones de doblado indican claramente el orden en el que fue plegado (figs. 3 y 4). Pero, en este caso, se dispone de un dato adicional, puesto que, en la pátina del plomo desplegado pero sin limpiar se aprecian las sombras de los signos de la sección con la que tenía contacto una vez plegado. Así, ku y tu se aprecian sobre el signo to y viceversa, mientras que e y $\mathbf{n}$ se aprecian sobre be y viceversa. Curiosamente, sobre las dos secciones exteriores de la lámina una vez plegada, también se aprecian restos de lo que podrían ser signos. Así, sobre te y ř una forma semicircular, quizás ge o r, y un aspa, quizás da o go, mientras que, en la sección opuesta, sobre $\mathbf{r}$ y ge se aprecian algunos posibles trazos.
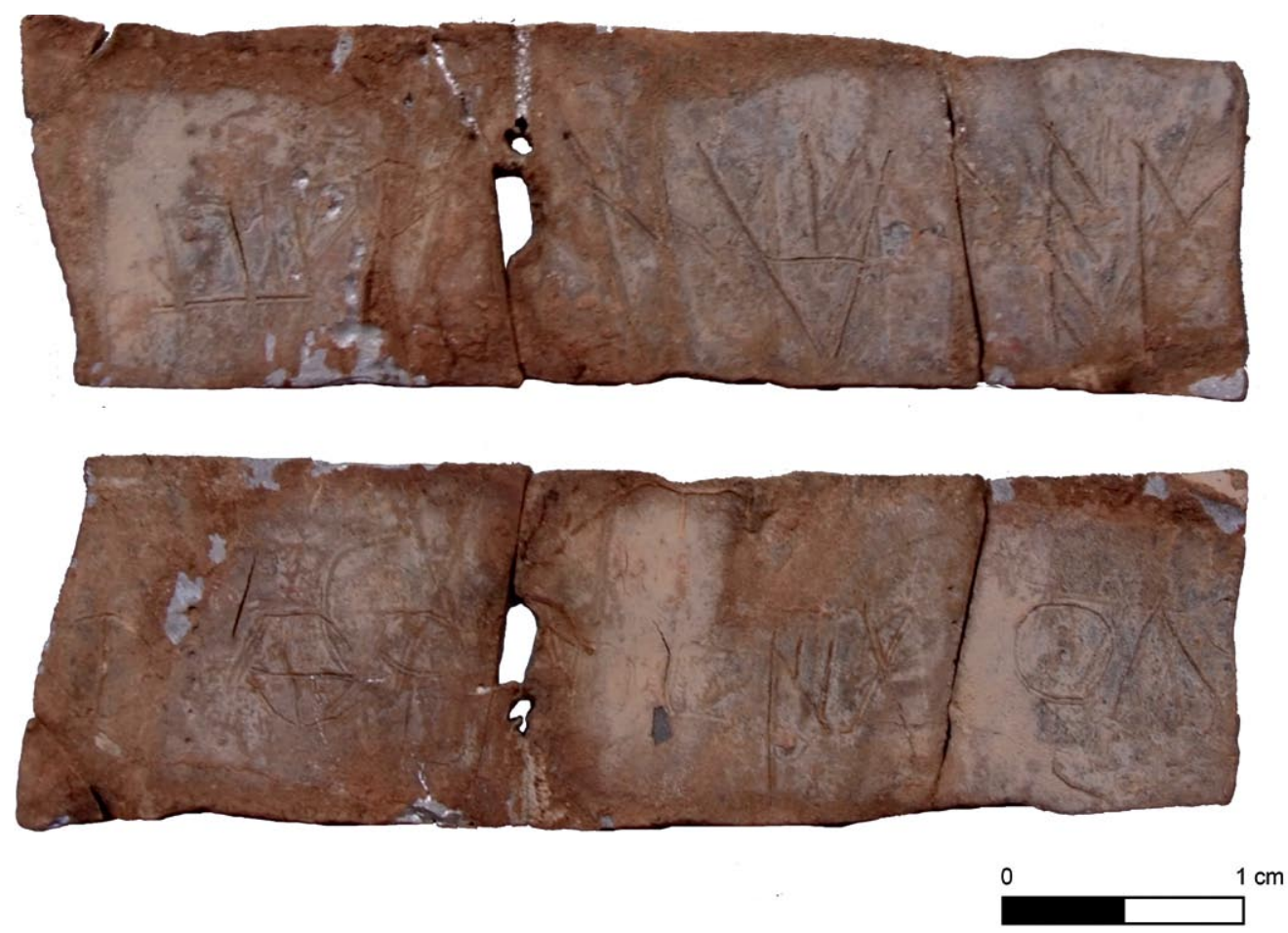

Figura 7. Plomo desplegado antes de la limpieza. Archivo SIP del Museu de Prehistòria de València.

Las láminas de plomo son un soporte específico para la escritura que no determina unívocamente la funcionalidad del texto, ya que puede ser muy variada ${ }^{5}$. Las características de esta lá-

5 Velaza (e. p.). 
mina la alejan de la mayor parte de casos conocidos, puesto que se trata de un texto muy breve que ocupa una sola línea, distribuido por ambas caras en un soporte de reducidas dimensiones, unos $5 \mathrm{~cm}$, y plegado dos veces generando tres secciones. Evidentemente, por su escasa longitud, ausencia de expresiones metrológicas y de texto exterior autónomo, no se trata de ningún texto comercial, ni administrativo o contable, ni de carta de ningún tipo. Tampoco se trata de una etiqueta, ya que presenta texto por ambas caras con indicios de continuidad en ambos textos y las marcas de plegado son compatibles con las que presentan las láminas plegadas en su uso primario.

Por su tamaño, y por estar escrito usando una sola línea, recordaría a las láminas del pozo votivo de El Amarejo (Bonete, Albacete) (BDH AB.06.01-04), aunque en aquel caso algunos de los fragmentos podrían formar un único texto más largo. Otros posibles paralelos serían los textos probablemente votivos del Llano de la Consolación (Montealegre del Castillo, Albacete) (BDH AB.07.05) en forma de ángulo recto, o el fragmento del Castellar de Meca (Ayora, València) (BDH V.15.02) de características compatibles, e incluso el plomo G.7.5 de forma ondulada de la Bastida de les Alcusses (Moixent, València) (BDH V.17.05). Todos los paralelos indicados están escritos en escritura ibérica suroriental, pero geográficamente son relativamente cercanos al Pico de los Ajos. No obstante, aun siendo de los más breves, todos ellos son más largos que el que nos ocupa: el del Llano de la Consolación es del orden del doble y con un texto corto visible en la cara exterior con el texto plegado, por lo que el mensaje debería ser más complejo, mientras que el de La Bastida es tres veces más largo con texto por ambas caras, sin que sea evidente la continuidad. En cualquier caso, todos estos ejemplos presentan trazas de haber sido también plegados. Otro posible paralelo, en este caso en escritura nororiental, sería la lámina del Tossal del Mor (Tàrrega, Lleida), de longitud solo algo mayor y también plegado, aunque en este caso con el texto distribuido solo en la cara interior en dos líneas siguiendo el borde, pero con un contenido formado exclusivamente por onomásticos (BDH L.17.01).

\section{LECTURA Y COMENTARIO PALEOGRÁFICO}

En el texto de la cara A, los primeros signos identificados son claros (figs. 8 y 9): to1 ${ }^{6}$ y ŕr 5 . El tercero probablemente sea un a3 afectado por una rotura en forma semicircular que ha hecho desaparecer la cabeza. De hecho, la rotura parece seguir el trazado semicircular del signo a3. Alternativamente, podría ser estrictamente ba1, aunque entonces quedaría más separado de lo normal del signo siguiente. Menos probablemente, también podría ser un ḿ $4 b$ o incluso un 12 . A continuación, los signos vuelven a ser claros, i3, un be7/8 de base triangular, 12, un e10 de cuatro trazos orientados hacia abajo. El signo final podría ser un $\mathbf{n} \mathbf{1}$, pero probablemente sea un ś1 con el trazo final desaparecido, puesto que de ser $\mathbf{n} 1$ no habría sido necesario alargar tanto el trazo final, que aparece cortado por el lateral del plomo. No obstante, la reconstrucción del signo ś1 sería ligeramente asimétrica, con la segunda mitad más ancha que la primera.

6 Si no se indica lo contrario, las codificaciones de signos hacen referencia a la clasificación de Untermann (1990, 246-247) en MLH III. 

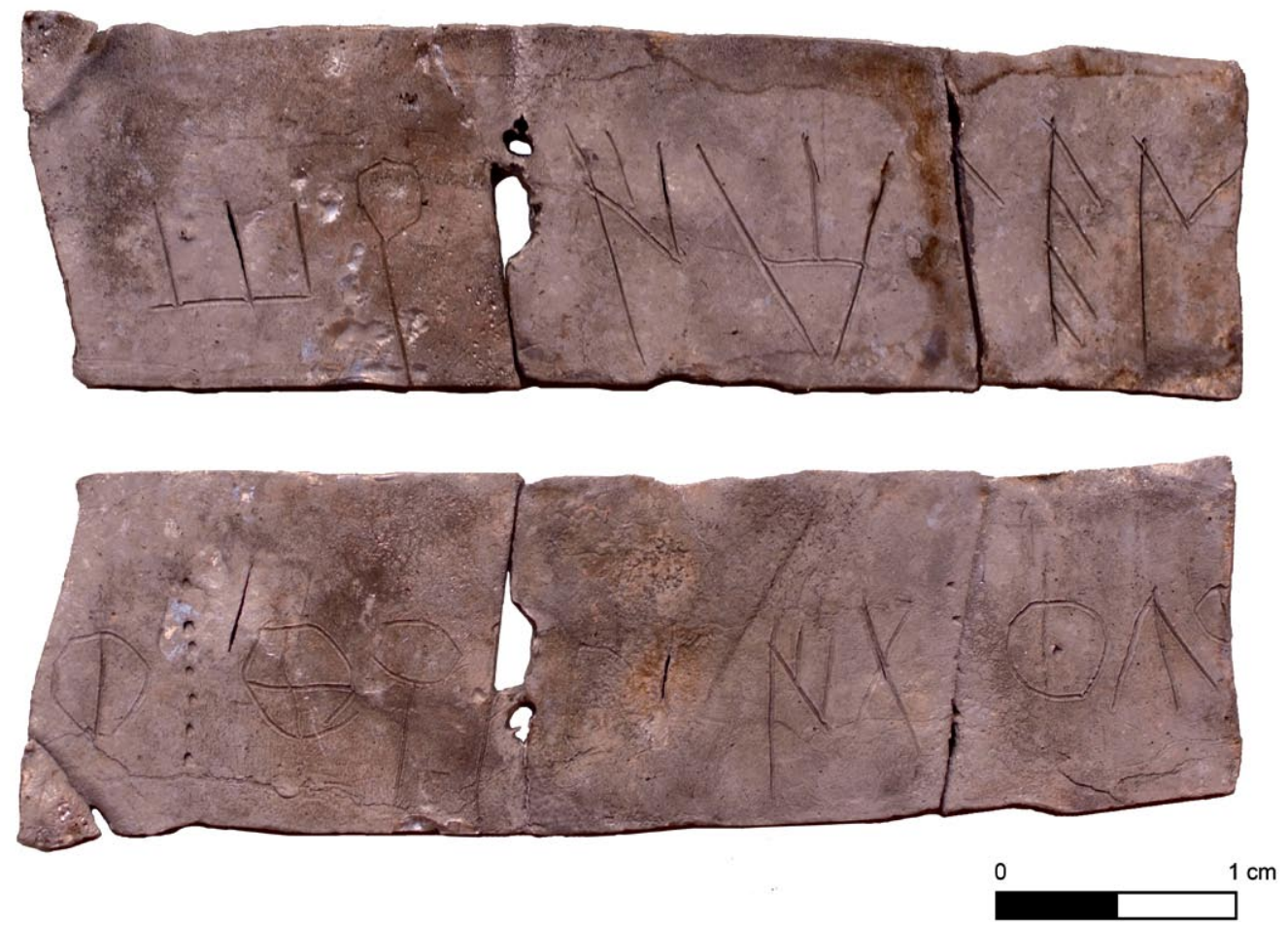

Figura 8. Fotografías el plomo después de la primera fase de la restauración. Archivo SIP del Museu de Prehistoria de València.

Por lo que respecta a la cara B, los primeros signos también son claros (figs. 8 y 9): te11, un separador de siete puntos, te 14 y $\mathbf{~} 5$. El cuarto signo es probablemente otro a 3 afectado por la misma rotura que dificulta la lectura del signo de la otra cara, aunque con el signo desplazado ligeramente hacia abajo, por lo que se puede apreciar el arranque del trazo semicircular de la cabeza. Estrictamente no se puede descartar la posibilidad que fuera un ḿ $4 \mathrm{~b}$, aunque no es la mejor opción entre las dos vibrantes, si se confirma la segunda. Los dos signos siguientes se distinguen con dificultad por haber sido afectados por la presencia de un elemento que los comprimió y disimuló sus trazos y que dejó su rastro como sombra en el plomo aún sin restaurar. Aun así, se puede identificar un $\mathbf{r} 5$ con el trazo inferior sobresaliendo un poco: menos probablemente podría tratarse de un a3 de pie bajo o a4, si los dos a 3 conflictivos no se confirmaran. El segundo es un ke7 de ángulo cerrado y trazos irregulares alargados. Los signos siguientes vuelven a ser claros: i3, ta1, un separador de al menos cinco puntos, ku2 y un signo tu sin base en forma de u4. El signo final es probablemente un signo í7 afectado por la rotura del lateral y del que solo es visible la mitad izquierda de la cabeza y la parte superior del trazo vertical, que no llega a rebasar el límite inferior de la cabeza. No es probable que se trate de un $\mathbf{r} 3$ de pequeńas dimensiones, puesto que, aunque con dudas, ya se ha identificado un $\mathrm{r} 5$ en este mismo texto. Además, en la parte superior a la derecha del trazo interior se aprecia el arranque del semicírculo de la mitad derecha de la cabeza del signo í 7 . 

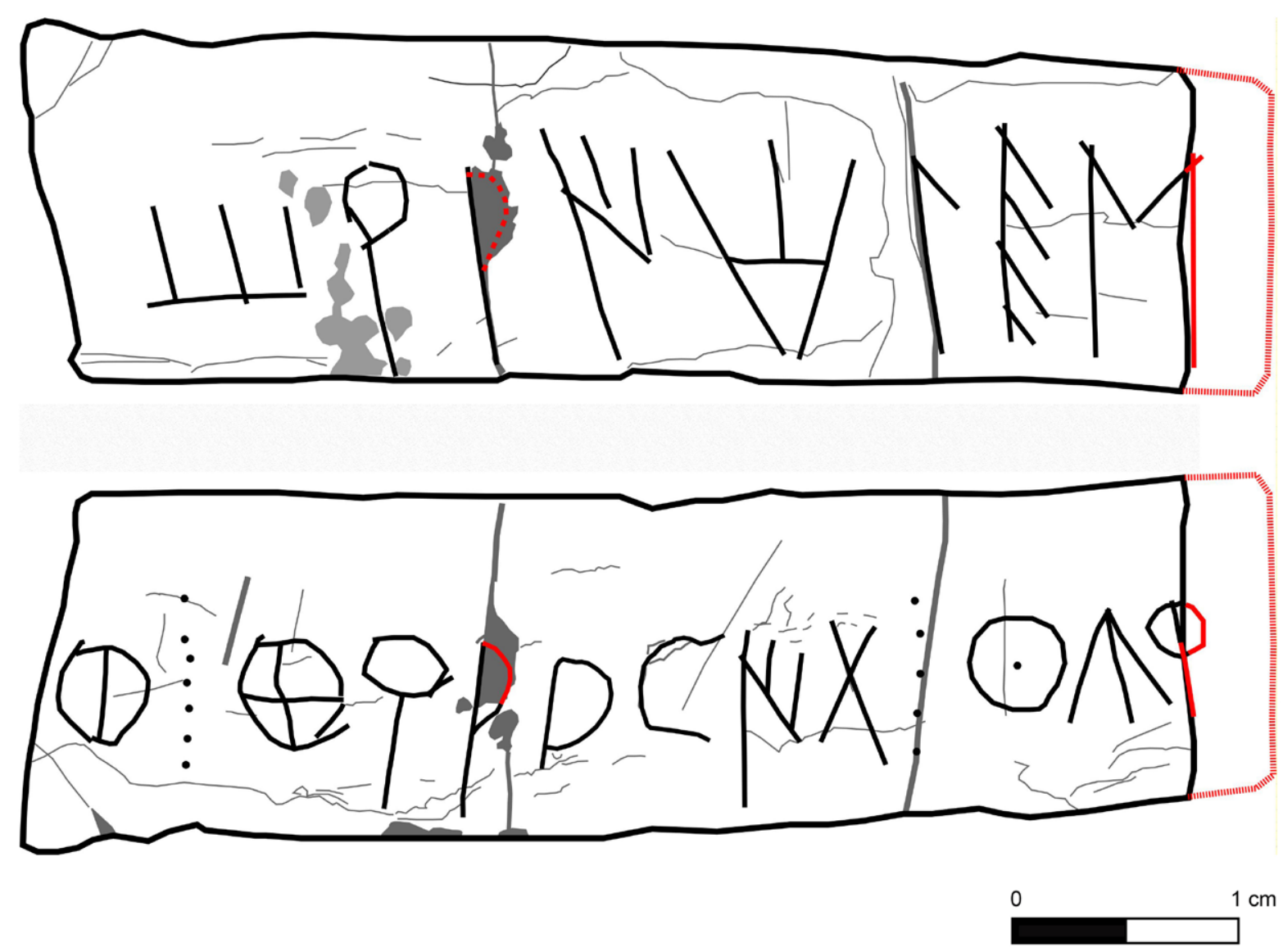

Figura 9. Dibujo del plomo por ambas caras.

Finalmente, cabe indicar que de los dos separadores que aparecen en la cara B, el primero está formado sin ninguna duda por siete puntos muy bien marcados, mientras que el segundo, con ciertas dudas por la fractura que afecta a los puntos inferiores, solo parece constar de cinco y algo menos marcados. En todo caso, la distancia entre el primero y el último puntos es similar en ambos separadores.

Así pues, asumiendo que el texto está completo, la lectura sería:

\section{to ráaibeleś-}

\section{de $\cdot$ ter̆argeida $\cdot$ kutuŕ}

Se trata de una inscripción dual, con una dualidad explícita entre las oclusivas, la del signo te, circunstancia remarcable teniendo en cuenta la escasa longitud del texto, por lo que pasa a formar parte de un grupo selecto de inscripciones (Ferrer i Jané 2015). Respecto de la lectura, la interpretación del signo to1 es controvertida, puesto que podría ser tanto la sorda, to, si su pareja fuese de dos trazos, como la sonora, do, si su pareja fuese de cuatro trazos (Ferrer i Jané 2019a). Algo parecido podría pasar con el signo tu sin base, puesto que en su uso en celtibérico en la tésera de 
Uxama (Osma, Soria) (BDH SO.06.02) podría corresponder a la sonora (Jordán 2005; Ferrer i Jané 2005), pero su aparición en primera posición de la dualidad del signo tu en los abecedarios duales de Ger (BDH GI.01.01c) y La Tor de Querol (BDH PYO.03.09) garantiza su condición de sorda en un contexto dual ibérico.

Respecto a la coherencia de uso del sistema dual, aunque el texto es breve y no hay muchos elementos conocidos susceptibles de ser comparados, el uso de las dualidades responde a lo esperado (Ferrer i Jané 2005, nota 4). En particular, kutuŕ sería coherente, puesto que aparece en la forma kutun en una inscripción dual de Oceja (BDH PYO.07.03; Ferrer i Jané 2018), mientras que en Llíria dos veces aparece como kutur (F.13.3 y F.13.35), pero otra como kudur (F.13.13). Además, si el paralelismo con el inicio de los abecedarios duales es correcto, las sordas aparecen por delante de las sonoras, por lo que kutu sería más verosímil que gudu, gutu o kudu (Ferrer i Jané 2014). También lo sería el uso de la dental sonora en el morfo -de del principio de la cara $\mathrm{B}$, si este es su uso delante del probable antropónimo de la cara A (Ferrer i Jané et al., e.p).

En este texto también se documenta una dualidad mucho menos frecuente, la de la vibrante ŕ, que se identifica tanto por el hecho de aparecer explícitamente en un grupo de inscripciones en el que coexisten las dos variantes de $\mathbf{r}^{7}$, como por su presencia en el abecedario ${ }^{8}$ del Tos Pelat (Burriel et al. 2011). Respecto de cuál sería el valor que habría detrás de esta oposición, teniendo en cuenta que la distinción de las oclusivas es entre lenis y fortis, todo hace pensar que en este caso diferencia la vibrante normal simple, ́́, probablemente alveolar, de la múltiple, $\check{\text { ŕ. }}$

Otro hito importante en la verificación de la existencia de esta dualidad en la escritura ibérica nororiental se ha producido recientemente por la aparición del plomo de Xàbia (Ferrer i Jané et al., e.p.), donde la casuística de uso de las dos vibrantes es bastante clara, de forma que ř aparece entre vocales, mientras que ŕ se usa delante de consonante y en posición final aparecen ambas, pero más frecuentemente ́́ , coincidiendo básicamente con el uso de esta dualidad en la escritura ibérica suroriental. En este nuevo texto del Pico de los Ajos, la distribución sería igualmente coherente, puesto que la vibrante no marcada ř aparece entre vocales, toŕaibeleś y teŕargeida, y la marcada en posición final, kutuŕ.

Por lo que respecta a la paleografía, destaca el carácter arcaico de muchas de las variantes usadas. Sería el caso de la variante de e de cuatro trazos orientados hacia abajo (e10a) que es muy poco frecuente. Esta variante se usa en la falcata procedente de Torres-Torres (BDH V.22.01), en una de las dos fusayolas de Oliete (BDH T.05.06), en el asa de la cerámica gris del Turó de Can Oliver (Cerdanyola del Vallès, Barcelona) (BDH B.20.06) y en tres inscripciones rupestres de Oceja (BDH PYO.07.07, 09 y 13). Las tres primeras, además, se caracterizan por la presencia de fenómenos paleográficos poco frecuentes, como sería la variante de ke compleja de la falcata, los signos a e i marcados del asa y la variante de tu sin base de la fusayola. Curiosamente, esta última característica también se repite en esta inscripción, aunque en la fusayola aparece en la forma de un $\mathbf{u} 2$ con el trazo interior incompleto, que en esta inscripción tiene la forma de un $\mathbf{u} 4$, con el trazo interior completo, tal como aparece los dos abecedarios duales de Ger (BDH GI.01.01c) y La Tor de Querol (BDH PYO.03.09).

En todo caso, la variante más interesante de esta inscripción es la variante inédita de be que tiene tres trazos superiores y la base en forma de triángulo con el vértice en su parte inferior $(\forall)$. Esta variante tendría como paralelos más cercanos la variante be8 ( () , con un círculo en lugar

7 Ferrer i Jané 2010, 101; 2013, 448; 2015, 321; 2017, 79; 2020a, 1001; Ferrer i Jané \& Moncunill 2019.

\footnotetext{
8 Los abecedarios o signarios son aquellas inscripciones que representan estrictamente al conjunto de signos de una determinada escritura.
} 
del triángulo, y be7 ( $)$ (BDH HER.02.022), con un círculo mal trazado que acaba pareciendo un triángulo. Estas variantes arcaicas (Maluquer 1968, 37; Rodríguez Ramos 2004, 109), que son características de las cerámicas áticas de Ullastret y en general de la zona costera de Catalunya (zona C) y del territorio ibérico del sur de Francia (zona B) en el siglo iv a.C. ${ }^{9}$, también presentan modelos con la base abierta, como be9 ( $($ ) (BDH GI.15.06) y $\Perp$ (BDH GI.15.35), que enlazarían con las variantes meridionales que corresponden a la segunda vibrante en la escritura ibérica suroriental $(\mathcal{K})$, y quizás también en la escritura del sudoeste $(\mathcal{W})$, pero con solo dos trazos, en lugar de tres. Y probablemente todas ellas podrían retrotraerse al modelo documentado por el signo 26 del signario de Espanca (㓞) girado $90 .^{\circ}$ a la izquierda y con cuatro trazos (Ferrer i Jané 2017, 69 y 72).

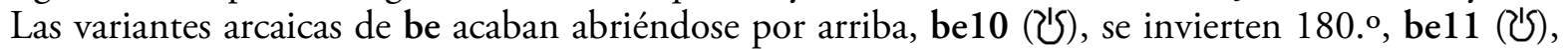
y finalmente pierden el trazo central, be2 $(\Omega)$, y se simplifican a la versión más moderna y rectilínea del signo bel $(\widehat{\wedge})$.

También cabe destacar la variante i3 con el trazo principal muy alargado, que sería compatible con una escritura dual ampliada que distinguiera dos variantes de i (Ferrer i Jané 2015, 335). Normalmente un trazado descuidado de i1 puede generar la variante i3 sin ningún significado especial; no obstante, en este caso parece que se ha trazado de longitud similar a los otros dos para dotar a este trazo adicional de la misma categoría. Si fuera así, esta variante sería probablemente la compleja, mientras que la variante simple podría ser un i1 sin el trazo inicial alargado, o quizá un i6, prescindiendo del trazo intermedio.

Así pues, la paleografía del texto es completamente diferente de la que ya se conocía por los otros plomos procedentes de este yacimiento, especialmente los tres más largos BDH V.13.01-03, incluyendo el texto oculto del primero (Ferrer i Jané 2021), de forma que, mientras que los plomos ya conocidos presentan una paleografía moderna característica de los siglos II-I a.C., este nuevo plomo presenta una paleografía más característica del siglo iv a.C. que del siglo iII a.C., e impensable en los siglos II-I a.C.

\section{Comentario lingüístico}

Como hemos señalado, es posible que, con la salvedad de los signos afectados por el corte a final de las dos líneas y que pueden ser identificados sin mayores problemas, la inscripción esté completa, y que, por lo tanto, hayamos de leer una secuencia de tres palabras:

\section{torrạibeleśde $\cdot$ teřărgeida $\cdot$ kutur}

Los elementos integrantes del texto serían los siguientes:

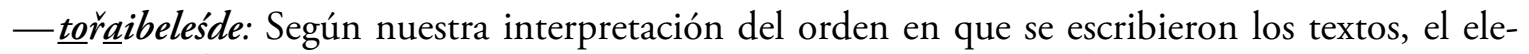
mento -de que inicia la cara B habría de ser continuación de la palabra de la cara A y, en consecuencia, habría de leerse como una secuencia única tor ráaibeleśde. La existencia de un sufijo

9 Cerámicas áticas: Ensérune, BDH HER.02.022 y BDH HER.02.025; Ruscino, BDH PYO.01.06; Elna, BDH PYO.02.18; Ullastret: BDH GI.15.18, BDH GI.15.15, BDH GI.15.15, BDH GI.15.24, BDH GI.15.35, BDH GI.15.36 y BDH GI.15.14; Pon- tós: BDH GI.08.04. Láminas de plomo: Montlaurés, BDH AUD.02.10; Ullastret, BDH GI.15.04 (6), BDH GI.15.05 y BDH GI.15.06. Cerámica gris: Sant Julià de Ramis, BDH GI.13.03. 
-te / -de es bien conocida, en general como acompañante de nombres personales (Moncunill \& Velaza 2019, 213), aunque todavía no está claro si se trata de un único sufijo o de dos diferentes, uno con la oclusiva sonora y otro con la sorda. Si bien en inscripciones en escritura dual, parece predominar la forma con la sonora, como, por ejemplo, en bilo[s]aŕkérdegiar (BDH B.20.04). En este nuevo texto, el sufijo se ańade a una secuencia torráaibeleś en la que se identifica con claridad el conocido formante antroponímico beleś (MLH III \$7.31). La secuencia precedente es menos transparente: un elemento de formación onomástica toó podría identificarse en secuencias como ban-toŕ-en-ḿi-baikar (BDH B.44.16) o en toŕbos (La Joncosa, BDH B.11.01), entre otros ejemplos. Si fuera así, quedaría por explicar la secuencia - $a$ i- que aparece entre ambos formantes: en este caso, las hipótesis son menos claras, pero cabe recordar que ya Untermann (1990) (MLH III \$510) había visto una posible alternancia morfológica en algunos formantes como berai- / beŕi- o sikai- / sike. En cualquier caso, todo parece apuntar a que en tórálbeleśde haya que ver una secuencia de NP-de.

- teřargeida: Secuencia de difícil análisis. No puede excluirse la posibilidad de identificar dos elementos de formación antroponímica (si teř fuera variante de taŕ (MLH III \$7.115) y arge o argei de aŕki $M L H$ III \$7.14), quizás con el morfo -ei (Moncunill \& Velaza 2019, 250), a los que se añadiría un sufijo -da / -ta que aparece en algunos topónimos, como Ilerda o Edeta (Moncunill \& Velaza 2019, 197-198), pero lo cierto es que podría tratarse también de una estructura no onomástica.

- kutuŕ: Se trata de la palabra más conocida del texto, aunque su forma original no está exenta de problemas (Ferrer i Jané 2014, 248; Moncunill \& Velaza 2019, 301). Este elemento casi siempre aparece en la forma kutur, pero ya se había documentado dos veces en la forma kutuŕ, una en el plomo de Gruissan (BDH AUD.04.02), que parece que invierte el uso de $\mathbf{r}$ y ́́, y otra en el plomo del Grau Vell de Sagunt (BDH V.04.61). Por sus contextos de aparición, parece tratarse de una palabra del léxico común y se la relaciona con el campo semántico de la escritura; dado que sus primeros signos reproducen el orden de los que inician los signarios ibéricos, tal vez incluso sea la palabra equivalente a «alfabeto» o «abecedario» en ibérico. Su aparición en textos probablemente religiosos conectaría con un uso votivo del signario en el mundo ibérico equivalente al que se conoce en otras culturas escritas del mundo antiguo (Velaza 2012 y 2019).

En consecuencia, la estructura de la secuencia estaría encabezada por un NP sufijado con -de seguido por una palabra indeterminada y el término conocido kutuŕ.

Si el segundo elemento fuese también un NP sufijado con - $d a$, tal vez en el texto se mencionen dos personajes, uno de nombre Toraibeles y otro de nombre Terargei, uno de los cuales, probablemente el primero, ofrende al otro un signario. La posibilidad de que uno de los dos onomásticos corresponda a un teónimo, quizás el segundo, no parece tampoco descartable en primera instancia. No obstante, la ausencia de los morfemas más característicos de las inscripciones votivas rupestres de La Cerdanya (Ferrer i Jané 2018; 2019b; 2020b), como e, para el que se supone una función como marca de dativo (Moncunill \& Velaza 2019, 236), no favorecería esta interpretación.

Alternativamente, se podría pensar en un esquema NP-de, seguido de una forma verbal (Moncunill \& Velaza 2019, 213), donde toráaibeleśs sería plausiblemente el agente de la acción, teřargeida, la forma verbal y kutuŕ, el objeto. No obstante, en contra de esta interpretación está el hecho de que teřargeida presenta más afinidades con los onomásticos que con las formas verbales conocidas. 


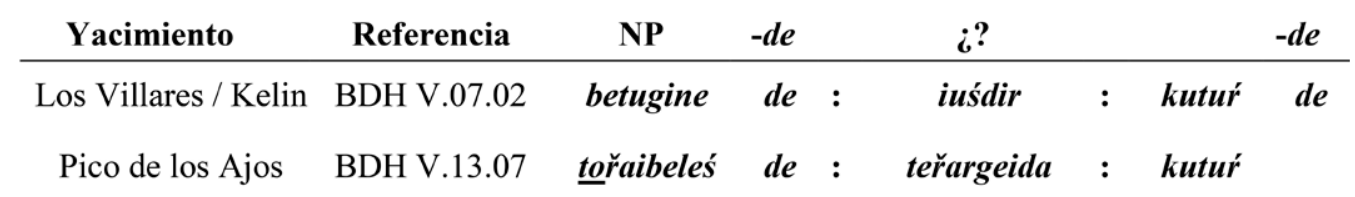

Figura 10. Comparativa de términos entre el plomo del Pico de los Ajos y el de Los Villares.

En todo caso, la nueva lectura del texto de la cara externa del segundo plomo de Los Villares/Kelin (BDH V.07.02) (fig. 11), sí que permitiría establecer un paralelo posicional con iunstir (fig. 10), que es uno de los candidatos a forma verbal, aunque en otros casos parece actuar como sustantivo (Moncunill \& Velaza 2019, 341). La lectura tradicional es betuginete - iuśdiŕ - aturde, pero la lectura correcta es betuginede - iuśdir - kutuŕde. Por una parte, se corrige el uso de la sonora, en lugar de la sorda, en el morfo - $d e$, que sería así coherente con el texto que encabeza la otra cara sakaŕadinde - iuśdir. Y por otra parte se identifica el elemento kutuŕ, que sería, con el nuevo texto del Pico de los Ajos, la cuarta ocurrencia con la vibrante cambiada. La mitad izquierda del signo ku está medio oculta por un pequeño pliegue y la pátina, pero la curvatura del trazo y el punto central son claros. La única diferencia sería la presencia en el texto de Los Villares de un morfo de detrás de kutuŕ, un morfo homógrafo, pero con alta probabilidad de ser funcionalmente distinto al que aparece con el antropónimo. No obstante, no sería completamente descartable la presencia del morfo de en el texto perdido de la cara B de la lámina del Pico de los Ajos, si fuera de pequeñas dimensiones (fig. 9).

En cualquier caso, nuestros conocimientos de la lengua ibérica son todavía muy limitados como para proponer la intelección de este tipo de textos, por lo que, naturalmente, todas estas especulaciones han de tomarse con la máxima prudencia.

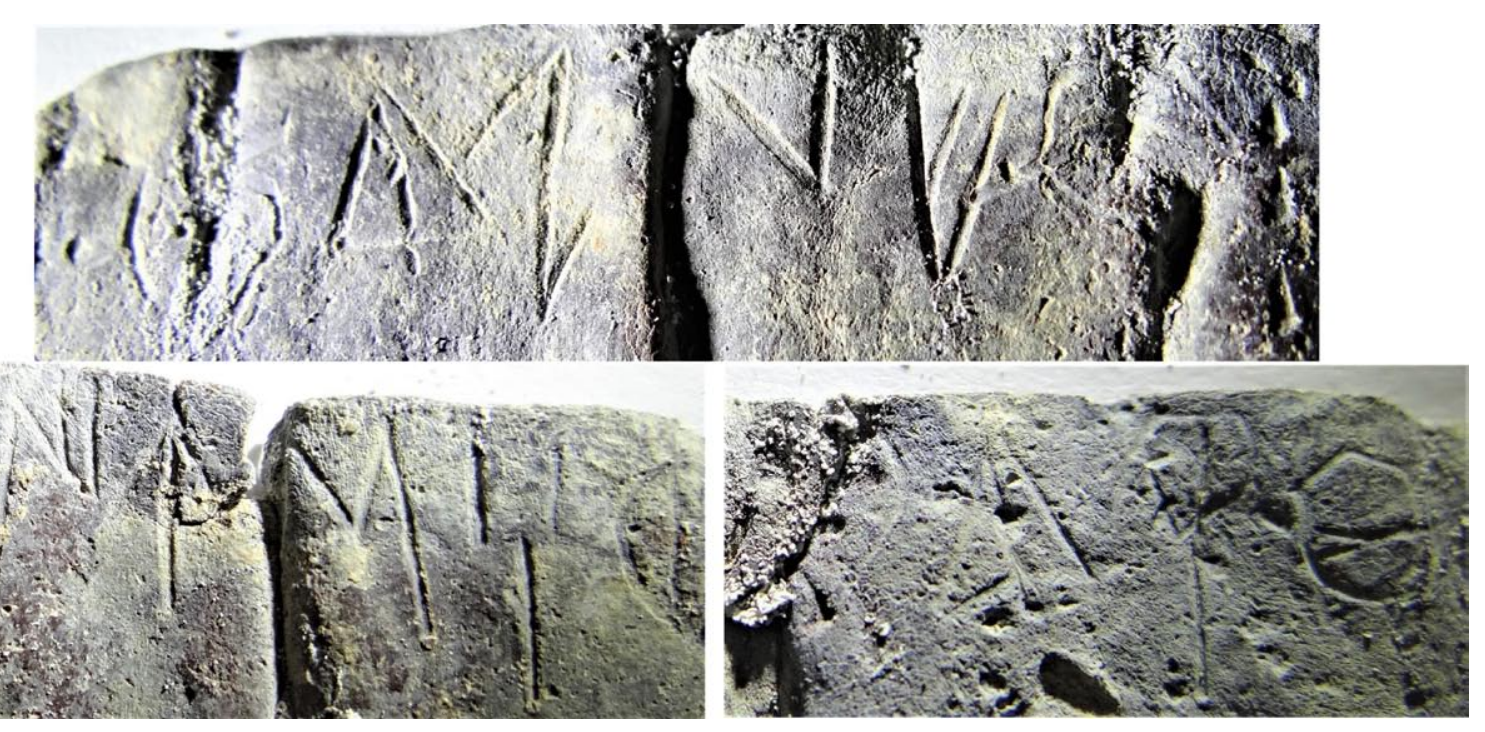

FIGURA 11. Fotografías de los segmentos del texto exterior de BDH V.07.02: betuginede · iuśdir · kutuŕde. 


\section{Conclusiones}

La lámina que aquí presentamos no tiene paralelos desde el punto de vista tipológico, puesto que combina características poco comunes: un soporte de pequeñas dimensiones, plegado sobre sí mismo, y un único texto muy breve, escrito por ambas caras, probablemente completo, aunque presenta un recorte antiguo de unos $5 \mathrm{~mm}$ de longitud. Las láminas del pozo votivo de El Amarejo en escritura ibérica suroriental serían su paralelo más cercano, aunque solo están escritas por una cara.

En estas circunstancias, es difícil establecer cuál sería la funcionalidad de la lámina. Por su morfología y lo que se desprende de su texto, parece obligado descartar que se trate de una carta o de un texto de función, lato sensu, comercial. Como se ha dicho, también parece menos probable que se trate de una etiqueta, puesto que está escrito por ambas caras y parte del texto no podía verse una vez plegado. Así, ganaría fuerza la hipótesis de que se trate de un epígrafe de tipo religioso, tal vez votivo, lo que se compadecería bien con la interpretación de kutuŕ como término vinculado al campo semántico de los abecedarios y, asimismo, a la interpretación de estos últimos como elementos religiosos.

El elemento tóráaibeleś es probablemente un antropónimo y el hecho de que vaya acompañado del morfo - de lo identificaría como el plausible autor de la inscripción. En cambio, el segundo elemento teŕargeida no presenta una interpretación clara, aunque su estructura es compatible con la de un onomástico complejo. En cualquier caso, el paralelo con la nueva lectura del texto de la cara B del segundo plomo de Los Villares lo situaría en posición similar a la de iuśdir en este texto, entre el esquema NP-de y el elemento kutuŕ.

Desde el punto de vista paleográfico, cabe señalar que se trata de un texto dualmente explícito ya que usa las dos variantes de te, circunstancia poco frecuente, especialmente en textos de tan escasa longitud como este. Además, también se documenta explícitamente la dualidad de la vibrante, relativamente frecuente en zona edetana en cronología antigua y presente esporádicamente en otras zonas. Ambas dualidades se usan de forma coherente con lo esperado, con las oclusivas sordas marcadas con un trazo adicional y, en el caso de la vibrante, ocupando la no marcada, la posición intervocálica.

La paleografía del texto es completamente diferente de la que ya se conocía por los otros plomos procedentes de este yacimiento. Así, mientras que los plomos previamente conocidos presentan una paleografía moderna característica de los siglos II-I a.C., este nuevo plomo presenta una paleografía más propia del siglo IV a.C. que del iII a.C., teniendo en cuenta la inédita variante de be, que recuerda a las variantes más arcaicas de Ullastret del siglo IV a.C.

La incorporación de técnicas analíticas en este tipo de trabajos aporta datos sobre procedencia de materias primas y manufacturación. Los resultados obtenidos por pXRF en PA-VII son similares a los del plomo escrito del Tos Pelat y coinciden con otros artefactos de plomo. No obstante, es necesario analizar un mayor número de piezas, empleando también técnicas analíticas complementarias (ej. Raman y colorimetría) para la obtención de datos más robustos que puedan avalar problemáticas relacionadas con procedencia de materias primas y/o procesos de manufacturación, para el desarrollo de hipótesis sobre intercambio de estos materiales entre territorios ibéricos.

El edificio donde apareció el plomo, a partir de la propia orografía del emplazamiento, el tipo de construcciones, la abundancia de recipientes de almacenaje y el inusual conjunto metálico de piezas de hierro, bronce y plomo rotas o inutilizadas, se interpreta como un espacio auxiliar donde, entre otras actividades, se hizo acopio de metal para posteriormente reciclarlo, ergo, chatarra (Serrano 2020). Este tipo de actividades apenas cuenta con paralelos para la Edad del Hierro, siendo más habituales en la Edad del Bronce (por ej. Delfino 2014). Por lo tanto, dicho contexto 
arqueológico explica bien tanto el hecho de que la lámina aparezca algo recortada como su paleografía arcaica en relación a su contexto de hallazgo. Sería claramente secundario, distinto del que inicialmente se pensó para la lámina escrita, siendo en ese momento solo un objeto metálico más. Curiosamente, este mismo patrón se repite con los tres plomos mayores del yacimiento, que también aparecen recortados por un mismo corte cuando ya formaban una unidad, aunque desafortunadamente se desconoce su contexto.

\section{BibLIOGRAFÍA}

Barrio, J., M. Arroyo, E. Cano, J. M. Bastida \& A. I. Pardo, 2005, Investigación sobre el proceso de estabilización y limpieza por reducción potenciostática de un plomo epigráfico romano, [Investigación en Conservación y Restauración], Barcelona: II Congreso GEIIC.

Bonet, H., \& C. Mata, 2002, El Puntal dels Llops. Un fortín edetano, [Serie de Trabajos Varios 99], València: Servicio de Investigación Prehistórica.

Burriel, J. M. a, C. Mata, J. Ferrer i Jané, A. L. Ruiz, J. Velaza, M. a Peiró, C. Roldán, S. Murcia \& A. Doménech, 2011, «El plomo escrito del Tos Pelat (Moncada, Valencia)», PalHisp 11, 191-224.

Degrigny, C., \& R. Le Gall, 1999, "Conservation of ancient lead artifacts corroded in organic acid environments: electrolytic stabilization/consolidation», Studies \& Conservation 44, 3, 157-169.

Delfino, D., 2014, «Bronze recycling during the Bronze Age: some consideration about two metallurgical regions", Antrope 1, 120-143.

Díaz, S., \& E. García, 2015, Proyecto Coremans: criterios de intervención en materiales metálicos, Madrid: Ministerio de Educación, Cultura y Deporte.

Díes, E., \& L. Gimeno, 1995, «El sistema defensivo de la zona SE del yacimiento ibérico del Pico de los Ajos (Yátova, Valencia)», SAGVNTVM-PLAV29, 85-92.

Ferrer i JANÉ, J., 2005, «Novetats sobre el sistema dual de diferenciació gràfica de les oclusives», en: F. Beltrán, C. Jordán, J. Velaza (eds.), Acta Palaeohispanica IX. Actas del IX Coloquio sobre Lenguas y Culturas Palaeohispánicas, Zaragoza: PalHisp 5, 957-982.

Ferrer i Jané, J., 2010, «El sistema dual de l'escriptura ibèrica sud-oriental», Veleia 27, 69-113.

Ferrer i Jané, J., 2013, "Els sistemes duals de les escriptures ibèriques», en: X. Ballester, F. Beltrán, F. J. Fernández Nieto, C. Jordán, J. Siles (eds.), Acta Palaeohispanica XI. Actas del XI Coloquio de Lenguas y Culturas Prerromanas de la Peninsula Ibérica, Valencia: PalHisp 13, 445-459.

FERrer I JaNÉ, J., 2014, «Ibèric kutu i els abecedaris ibèrics», Veleia 30, 227-259.

FERRER I JANÉ, J., 2015, «Las dualidades secundarias de la escritura ibérica nororiental», ELEA 14, 309-364.

FERrer i JANÉ, J., 2017, «El origen dual de las escrituras paleohispánicas: un nuevo modelo genealógico», en: F. Beltrán, B. Díaz, M. J. Estarán, C. Jordán, A. Klöckner, T. Schattner (eds.), Acta Palaeohispanica XII. Bild und Schrift. Medienkombinationen in den eisenzeitlichen Kulturen Hispaniens. Kolloquium zu ehren von Jürgen Untermann, Zaragoza: PalHisp 17, 55-94.

Ferrer i Jané, J., 2018, «A la recerca dels teònims ibèrics. A propòsit d'una nova lectura d'una inscripció ibèrica rupestre d'Oceja (Cerdanya)", en: Studia Philologica et Diachronica in Honorem Joaquin Gorrochategui. Indoeuropaea et Palaeohispanica, 101-126.

Ferrer I Jané, J., 2019a, "A la recerca del trial: Les variants supercomplexes de les escriptures paleohispàniques», PalHisp 19, 27-53.

Ferrer i JanÉ, J., 2019b, "Construint el panteó ibèric amb l'ajut de les inscripcions ibèriques rupestres», $\operatorname{Ker} 13,42-57$.

Ferrer i Jané, J., 2020a, «Las escrituras epicóricas de la Península Ibérica», PalHisp 20, 969-1016. https:// doi.org/10.36707/palaeohispanica.v0i20.385

FERrer I JANÉ, J., 2020b, «Urdal: Une nouvelle inscription rupestre ibère à Ger (Cerdagne) avec une possible divinité zoomorphe liée au sanglier, Sources», Les Cahiers de l'Âne Rouge 7, 17-28. 
Ferrer i Jané, J., 2021, «El texto oculto del segundo plomo ibérico del Pico de los Ajos (Yátova, València)», Veleia 38.

Ferrer i Jané, J., \& N. Moncunill, 2019, «Palaeohispanic writing systems: classification, origin and development», en: J. Velaza, A. G. Sinner (ed.), Palaeohispanic Languages and Epigraphies, Oxford, 78-108.

Ferrer i Jané, J., N. Moncunill, V. Sabaté \& J. Velaza, «Plomo ibérico del Museo de Xàbia», AEspArq.

Fletcher, D., 1980, Los plomos ibéricos de Yátova, [Serie Trabajos Varios 81], València: Servicio de Investigación Prehistórica.

Fletcher, D, 1982, «Nuevos plomos ibéricos valencianos», Arse 17, 252-259.

Fletcher, D, 1985, Textos ibéricos del Museo de Prehistoria de Valencia, [Serie Trabajos Varios 66], València: Servicio de Investigación Prehistórica.

Forrières, C., 2001, «La conservation des plombs anciens», en: C. Volfovsky (dir.), La conservation des métaux, Paris: CNRS Éditions, 147-151.

Jordán, C., 2005, «¿Sistema dual de escritura en celtibérico?», en: F. Beltrán, C. Jordán y J. Velaza (eds.), Acta Palaeohispanica IX. Actas del IX Coloquio sobre Lenguas y Culturas Paleohispánicas, Zaragoza: PalHisp 5, 1013-1030.

Maluquer de Motes, J., 1968, Epigrafía prelatina de la peninsula ibérica, Barcelona.

Mata, C., L. Soria, M. Blasco, G. Gallello, M. C. Belarte \& A. Pastor, 2020, «El prestigio de los objetos: mangos de marfil en el mundo ibérico», Zephyrus 86, en prensa.

Moncunill, N., \& J. Velaza, 2019, Monumenta Linguarum Hispanicarum Band V.2 Lexikon der iberischen Inschriften. Léxico de las inscripciones ibéricas, Wiesbaden.

Quixal, D., 2010, «El Pico de los Ajos (Yátova) y el poblamiento ibérico en torno a los ríos Magro y Mijares», Revista de Estudios Comarcales Buñol-Chiva 9, 25-35.

Quixal, D., 2012, «El valle del Magro como vía de comunicación en época ibérica (siglos vi-I a.C.)», APL XXIX, 187-208.

Quixal, D., C. Mata \& C. Martínez, 2018, «Primera campaña de excavación en el poblado ibérico del Pico de los Ajos (Yátova, Valencia)», SAGVNTVM-PLAV 50, 247-250. https://doi.org/10.7203/ SAGVNTVM.50.125

Quixal, D., C. Mata \& A. Serrano, 2019, «Un edificio de uso artesanal en el poblado ibérico del Pico de los Ajos (Yátova, València)», SAGVNTVM-PLAV 51, 261-264. https://doi.org/10.7203/ SAGVNTVM.51.158

RodríGuez Ramos, J., 2004, Análisis de epigrafía íbera, Vitoria-Gasteiz: UPV/EHU.

Rubio-Barberá, S., J. Fragoso, G. Gallello, F. Arasa. M. Lezzerini, E. Hernández, A. PasTOR \& M. DE LA GuARDia, 2019, "Analysis of Sagunto Ibero-Roman votive bronze statuettes by portable X-ray fluorescence», Radiation Physics and Chemistry 159, 17-24. https://doi.org/10.1016/j. radphyschem.2019.02.031

Serrano, A., 2020, Un depósito metalúrgico en el sector 4 del Pico de los Ajos (Yátova, Valencia), Trabajo Final de Máster, Universitat de València.

Tomás, I., 1989, «Disco de plomo, escrito, del Pico de los Ajos (Yátova, Valencia)», APL XIX, 263-300.

Untermann, J., 1990, Monumenta Linguarum Hispanicarum, III Die iberischen Inschriften aus Spanien, Wiesbaden.

VeLAZA, J., 2012, «Inscripciones paleohispánicas con signarios», ELEA 12, 151-164.

Velaza, J., 2019, "Non solo lettere: l'alfabeto come elemento rituale nel mondo antico», en G. Baratta (ed.), L'ABC di un impero. Iniziare a scrivere a Roma, Roma, 121-138.

VelazA, J., e. p., «La epigrafía paleohispánica sobre láminas de plomo: algunas reflexiones generales», en Plumbum litteratum. L'escriptura sobre plom a l'època romana. 